\title{
Gastric bypass surgery has a weight-loss independent effect on post-challenge serum glucose levels
}

\author{
Dag Hofs $\varnothing^{1}$, Kåre I. Birkeland ${ }^{2,3}$, Jens J. Holst ${ }^{4}$, Jens Bollerslev ${ }^{3,5}$, Rune Sandbu 1,6, Jo Røislien 1,7 \\ and Jøran Hjelmesæth ${ }^{1,3^{*}}$
}

\begin{abstract}
Background: Gastric bypass surgery seems to have an effect on glucose metabolism beyond what is mediated through weight reduction. The magnitude of this effect on fasting and post-challenge glucose levels remains unknown.

Results: Morbidly obese subjects without known diabetes performed a $75 \mathrm{~g}$ oral glucose tolerance test before and after either gastric bypass surgery $(n=64)$ or an intensive lifestyle intervention programme $(n=55)$, ClinicalTrials.gov identifier NCT00273104. The age-adjusted effects of the therapeutic procedures and percentage weight change on fasting and 2-h glucose levels at 1 year were explored using multiple linear regression analysis. Mean (SD) serum fasting and 2-h glucose levels at baseline did not differ between the surgery and lifestyle groups. Weight-loss after surgical treatment and lifestyle intervention was $30(8)$ and $9(10) \%(p<0.001)$. At 1 year, fasting and 2-h glucose levels were significantly lower in the surgery group than in the lifestyle group, $4.7(0.4)$ versus $5.4(0.7) \mathrm{mmol} / \mathrm{l}$ and $3.4(0.8)$ versus $6.0(2.4) \mathrm{mmol} / \mathrm{l}$, respectively (both $p<0.001$ ). Gastric bypass and weight-loss had both independent glucoselowering effects on 2-h glucose levels [B (95\% Cl) $1.4(0.6-2.3) \mathrm{mmol} / \mathrm{l}$ and $0.4(0.1-0.7) \mathrm{mmol} / \mathrm{l}$ per $10 \%$ weight-loss, respectively]. Fasting glucose levels were determined by weight change $[0.2(0.1-0.3) \mathrm{mmol} / \mathrm{l}$ per $10 \%$ weight-loss] and not by type of treatment.
\end{abstract}

Conclusions: Gastric bypass surgery has a clinically relevant glucose-lowering effect on post-challenge glucose levels which is seemingly not mediated through weight-loss alone.

Keywords: Morbid obesity, Hypoglycaemia, Gastric bypass surgery

\section{Background}

Reduction in blood glucose levels after gastric bypass surgery is related to weight-loss [1, 2]. In addition, a weight-loss independent effect of the surgical procedure on glucose metabolism has been hypothesized [2, 3]. Exaggerated post-prandial insulin secretion observed after gastric bypass supports this hypothesis [4-7]. The relative effects of weight loss and the surgical procedure per se on fasting and post-challenge glucose levels remain, however, unknown.

\footnotetext{
*Correspondence: joran.hjelmeseth@siv.no

${ }^{1}$ Morbid Obesity Centre, Vestfold Hospital Trust, post box 2168,

3103 Tønsberg, Norway

Full list of author information is available at the end of the article
}

The aim of the present analysis was to assess the effects of weight-loss achieved by gastric bypass surgery and lifestyle intervention on 1 year fasting and 2-h glucose levels. Data from oral glucose tolerance tests (OGTTs) in the previously published "Morbid Obesity treatment, Bariatric surgery versus Intensive Lifestyle intervention" (MOBIL) study [1] were analysed. The inclusion of a non-surgical weight-loss group made it possible to assess the specific effect of the surgical procedure on fasting and post-challenge glucose levels. To our knowledge, this has previously only been addressed in a few small studies $[8,9]$. 


\section{Methods}

This is a post hoc analysis of data from the MOBIL study [1] conducted at a public tertiary care centre in Norway. The trial included 146 morbidly obese subjects of mainly European descent, and aimed to address changes in several health outcomes related to obesity after gastric bypass surgery or an intensive lifestyle intervention programme. A 75 g 2-h OGTT was performed in subjects without known diabetes (119 out of 139 completers) at the time of inclusion. The present analyses include data from these participants. Some of the previously published data are included in the present paper as they are essential for interpretative purposes $[1,7]$.

Patients in the surgery group received laparoscopic Roux-en-Y gastric bypass, whereas patients who chose lifestyle intervention were referred to a rehabilitation centre specialising in the care of morbidly obese patients (Evjeklinikken A/S, Evje, Norway). The 1 year lifestyle programme at the rehabilitation centre aimed to induce a weight-loss of at least $10 \%$ and comprised of four stays at the centre lasting for either 1 or 4 weeks (total 7 week stay).

The regional ethics committee of the Southern Norway Regional Health Authority approved the study. The study is registered in the ClinicalTrials.gov-registry under the unique trial number NCT00273104. Written informed consent was provided by all participants.

Data are presented as mean (SD) or number (\%). Unadjusted between-group comparisons were assessed using either independent samples $t$ test or the Chi square test. Multiple linear regression analyses were used to assess the associations between treatment choice and weight change on serum glucose levels at 1 year. Due to age differences between the groups at baseline and the known impact of age on both fasting and 2-h glucose levels, the effects of the independent variables were age-adjusted. Interaction terms between the two explanatory variables (group and weight change) were included. Due to a standardised residual of 4.81 one case was excluded from the correlation and regression analyses including 2-h glucose as the dependent variable. The significance level was $\mathrm{p}<0.05$. Statistical analyses were performed using SPSS 17.0 (SPSS Inc., Chicago, IL, USA).

\section{Results}

Patients in the surgery group were younger [41 (10) versus 46 (11) years, $\mathrm{p}=0.007$ ], heavier [47 (6) versus 43 (5) $\left.\mathrm{kg} / \mathrm{m}^{2}, \mathrm{p}<0.001\right]$ and had greater weight-loss at one-year follow-up [30 (8) versus 9 (10) \%, p < 0.001]. The proportion of females did not differ between the surgery and lifestyle groups (70 versus $71 \%, \mathrm{p}=0.943$ ). Fasting and 2 -h glucose levels at baseline did not differ between the surgery and lifestyle groups, 6.1 (1.6) versus 6.0 (1.0) $\mathrm{mmol} / \mathrm{l}, \mathrm{p}=0.495$ and 7.5 (3.4) versus 7.6 (3.1) $\mathrm{mmol} / \mathrm{l}$, $\mathrm{p}=0.887$. In contrast, both fasting and 2-h glucose levels were significantly lower in the surgery group than in the lifestyle group at 1 year, $4.7(0.4)$ versus $5.4(0.7) \mathrm{mmol} / \mathrm{l}$ and $3.4(0.8)$ versus $6.0(2.4) \mathrm{mmol} / \mathrm{l}$ (both $\mathrm{p}<0.001)$.

The correlations between percentage weight change and fasting and 2-h glucose levels 1 year after surgical and medical treatment are shown in Fig. 1. Weight change correlated significantly with fasting glucose levels at 1 year in both groups. Further, the independent effects of treatment choice (group) and weight change on fasting and 2-h glucose levels were explored in two regression models (Table 1 ). Gastric bypass surgery had an independent effect on 2 -h glucose levels but not on fasting glucose levels at 1 year (Table 1). Nine percent
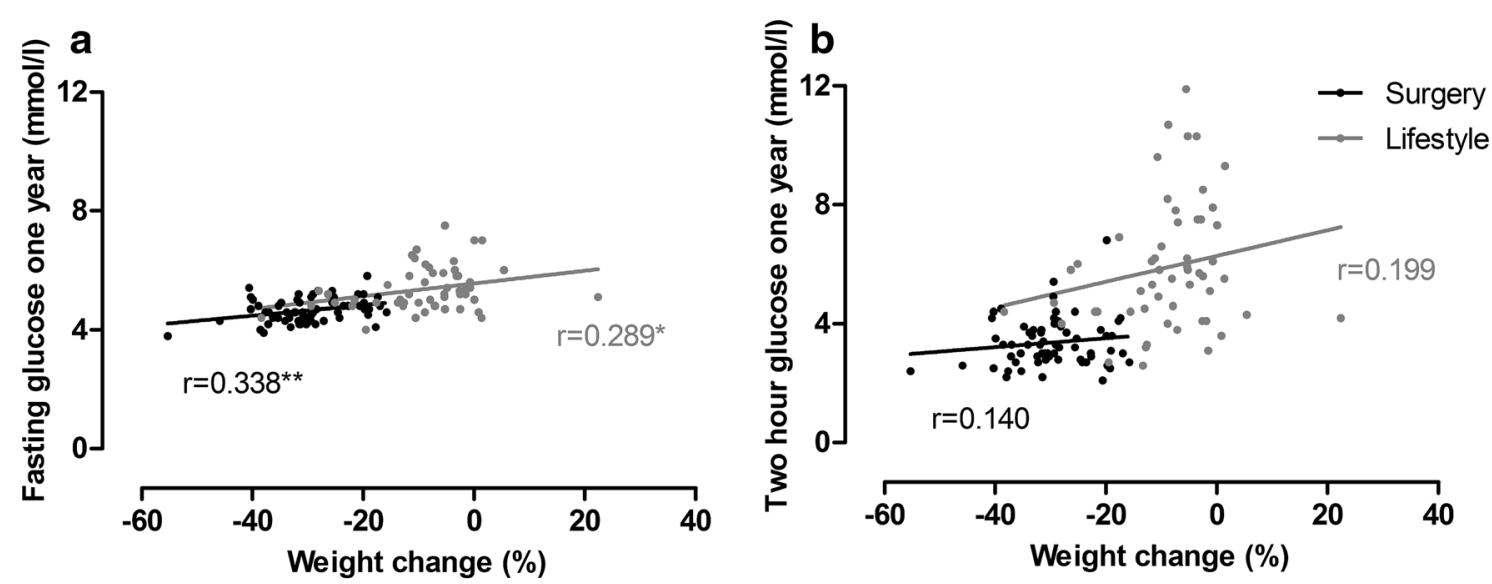

Fig. 1 Correlations between percentage weight change and fasting and 2 -h glucose levels at 1 year in the surgery and lifestyle groups. ${ }^{* *} p<0.01$, ${ }^{*} p<0.05$ 
Table 1 Multiple linear regression analyses with treatment choice, weight change and age as explanatory variables and fasting and 2-h serum glucose levels at 1 year as outcome variables

\begin{tabular}{|c|c|c|c|c|c|c|}
\hline & \multicolumn{3}{|l|}{ Fasting serum glucose } & \multicolumn{3}{|l|}{ 2-h serum glucose } \\
\hline & B $(95 \%$ Cl) & $\begin{array}{l}\text { Squared partial } \\
\text { correlation }\end{array}$ & $P$ value & B $(95 \%$ Cl) & $\begin{array}{l}\text { Squared partial } \\
\text { correlation }\end{array}$ & $P$ value \\
\hline Group & $0.118(-0.177$ to 0.414$)$ & 0.005 & 0.429 & $1.443(0.585-2.301)$ & 0.089 & 0.001 \\
\hline Weight change (\%) & $0.022(0.012-0.033)$ & 0.132 & $<0.001$ & $0.038(0.007-0.068)$ & 0.049 & 0.017 \\
\hline Age (years) & $0.022(0.013-0.031)$ & 0.177 & $<0.001$ & $0.054(0.028-0.079)$ & 0.132 & $<0.001$ \\
\hline
\end{tabular}

Group: surgery $=0$, lifestyle $=1$

of the variance in 2 -h glucose was explained by treatment choice. The mean $(95 \% \mathrm{CI})$ glucose-lowering effect of surgical treatment on 2-h glucose was $1.4(0.6-2.3)$ $\mathrm{mmol} / \mathrm{l}$. The distance between the group-specific correlation lines in Fig. 1b visualises this effect. Weight change per se was independently associated with both fasting and 2-h glucose levels and explained 13 and $5 \%$ (squared partial correlation) of the variance in the two glucose variables, respectively (Table 1). A $10 \%$ weight loss was associated with a reduction in fasting glucose of approximately $0.2 \mathrm{mmol} / \mathrm{l}$ and a reduction in 2-h glucose of approximately $0.4 \mathrm{mmol} / \mathrm{l}(\mathrm{B} \times 10$, Table 1$)$. The associations between weight change and fasting and 2-h glucose levels in the two groups did not differ significantly (no "group $\times$ weight change" interactions, $\mathrm{p}=0.371$ and $\mathrm{p}=0.130$, respectively). Age was positively associated with both fasting glucose levels and 2-h glucose levels and explained 18 and $13 \%$ of the variance in the respective glucose variables (Table 1). Overall, treatment choice, weight change and age explained $46 \%\left(R^{2}=0.459\right)$ and $49 \%\left(R^{2}=0.491\right)$ of the variance in fasting and 2-h glucose levels 1 year after treatment.

\section{Discussion}

The main finding of the present study is that gastric bypass surgery seems to have an effect on post-challenge glucose levels that is partly independent of weight loss, while the effect on fasting glucose levels is solely dependent on the degree of weight loss.

These results support the idea that gastric bypass surgery has a direct effect on glucose metabolism beyond what is mediated by weight change [3]. However, the effect seems to be specific for the post-prandial phase. In line with previous studies the procedure does not seem to have an independent effect on fasting glucose levels $[8,9]$. Improved fasting glucose is likely to be caused by reduced endogenous hepatic glucose production associated with weight-loss [10]. Contrasting our findings, changes in post-prandial glucose did not differ significantly after $10 \%$ weight-loss induced by either gastric bypass or lifestyle intervention [9]. However, the study seems inadequately powered $(\mathrm{n}=20)$ for detecting clinically relevant differences in post-prandial glucose levels. Supra-physiological post-prandial insulin secretion [47], possibly due to alteration of the gastrointestinal tract [11] with rapid glucose absorption [4] and exaggerated incretin response [4-6], may possibly explain the weightloss independent effect of gastric bypass on 2-h glucose levels observed in the present study.

The weight-loss independent glucose lowering effect of gastric bypass surgery on 2-h glucose levels might be beneficial in subjects with post-prandial hyperglycaemia. However, the potent effect of gastric bypass on post-challenge glycaemia may also increase the risk of post-prandial hypoglycaemia. This side effect is increasingly recognised to be a potential result of gastric bypass surgery [12]. Age and weight change were both significantly and positively associated with 2 -h glucose. These findings may suggest that younger subjects who experience large weight reduction after surgery may have an increased risk of developing post-prandial hypoglycaemia.

Most of the patients included in this analysis had glucose levels within the normal or pre-diabetic range, meaning that the results cannot be generalised to include patients with overt diabetes. Due to the non-randomised design of the study we cannot exclude that betweengroup differences may have confounded our interpretation of the data. However, no differences in glucose levels at baseline were observed. Moreover, statistical adjustments for differences in age between the two groups were performed in order to minimise any confounding.

\section{Conclusions}

The strong post-challenge glucose lowering effect of gastric bypass surgery on 2 -h glucose is partly independent of weight-loss. This finding supports the presence of gastric bypass specific glucose regulatory mechanisms.

\section{Abbreviations}

OGTT: oral glucose tolerance tests; MOBIL: morbid obesity treatment, bariatric surgery versus intensive lifestyle intervention. 


\section{Authors' contributions}

$\mathrm{DH}, \mathrm{JB}, \mathrm{RS}$ and JH contributed to the study design. RS performed or supervised the operations. DH analysed the data and drafted the manuscript. DH, JH and RS organised and conducted the study. All authors helped planning the analysis, interpreting the data, and revising the manuscript. All authors read and approved the final manuscript.

\section{Author details}

${ }^{1}$ Morbid Obesity Centre, Vestfold Hospital Trust, post box 2168, 3103 Tønsberg, Norway. ${ }^{2}$ Department of Endocrinology, Morbid Obesity and Preventive Medicine, Oslo University Hospital, Oslo, Norway. ${ }^{3}$ Faculty of Medicine, University of Oslo, Oslo, Norway. ${ }^{4}$ Department of Biomedical Sciences, Endocrinology Research Section, Copenhagen, Denmark. ${ }^{5}$ Section of Endocrinology, Department of Medicine, Oslo University Hospital Rikshospitalet, Oslo, Norway. ${ }^{6}$ Department of Surgery, Vestfold Hospital Trust, Tønsberg, Norway. ${ }^{7}$ Department of Biostatistics, Institute of Basic Medical Sciences, University of Oslo, Oslo, Norway.

\section{Acknowledgments}

We thank Berit Mossing Bjørkås, Linda Mathisen and Heidi Omre Fon at the Morbid Obesity Centre at Vestfold Hospital Trust for their assistance with sampling and logistics.

\section{Compliance with ethical guidelines}

\section{Competing interests}

The authors declare that they have no competing interests.

Received: 6 May 2015 Accepted: 11 August 2015

Published online: 22 August 2015

\section{References}

1. Hofso D, Nordstrand N, Johnson LK, Karlsen TI, Hager H, Jenssen T, Bollerslev J, et al. Obesity-related cardiovascular risk factors after weight loss a clinical trial comparing gastric bypass surgery and intensive lifestyle intervention. Eur J Endocrinol. 2010;163:735-45.

2. Dixon JB, le Roux CW, Rubino F, Zimmet P. Bariatric surgery for type 2 diabetes. Lancet. 2012;379:2300-11.

3. Cummings DE, Overduin J, Foster-Schubert KE. Gastric bypass for obesity: mechanisms of weight loss and diabetes resolution. J Clin Endocrinol Metab. 2004;89:2608-15.
4. Jacobsen SH, Bojsen-Moller KN, Dirksen C, Jorgensen NB, Clausen TR, Wulff $\mathrm{BS}$, et al. Effects of gastric bypass surgery on glucose absorption and metabolism during a mixed meal in glucose-tolerant individuals. Diabetologia. 2013;56:2250-4.

5. Dirksen C, Bojsen-Moller KN, Jorgensen NB, Jacobsen SH, Kristiansen VB, Naver LS, et al. Exaggerated release and preserved insulinotropic action of glucagon-like peptide-1 underlie insulin hypersecretion in glucose-tolerant individuals after Roux-en-Y gastric bypass. Diabetologia. 2013;56:2679-87.

6. Salehi M, Gastaldelli A, D'Alessio DA. Blockade of glucagon-like peptide 1 receptor corrects postprandial hypoglycemia after gastric bypass. Gastroenterology. 2014;146:669-80.

7. Hofso D, Jenssen T, Bollerslev J, Ueland T, Godang K, Stumvoll M, et al. Beta cell function after weight loss: a clinical trial comparing gastric bypass surgery and intensive lifestyle intervention. Eur J Endocrinol. 2001;164:231-8

8. Jackness C, Karmally W, Febres G, Conwell IM, Ahmed L, Bessler M. Very low-calorie diet mimics the early beneficial effect of Roux-en-Y gastric bypass on insulin sensitivity and beta-cell Function in type 2 diabetic patients. Diabetes. 2013:62:3027-32.

9. Vetter ML, Wadden TA, Teff KL, Khan Z, Carvajal R, Ritter S, et al. GLP-1 plays a limited role in improved glycemia shortly after Roux-en-Y gastric bypass: a comparison to intensive lifestyle modification. Diabetes. 2015:64:434-46.

10. Immonen H, Hannukainen JC, Iozzo P, Soinio M, Salminen P, Saunavaara V, et al. Effect of bariatric surgery on liver glucose metabolism in morbidly obese diabetic and non-diabetic patients. J Hepatol. 2014;60:377-83.

11. McLaughlin T, Peck M, Holst J, Deacon C. Reversible hyperinsulinemic hypoglycemia after gastric bypass: a consequence of altered nutrient delivery. J Clin Endocrinol Metab. 2010;95:1851-5.

12. Goldfine AB, Mun EC, Devine E, Bernier R, Baz-Hecht M, Jones DB, et al. Patients with neuroglycopenia after gastric bypass surgery have exaggerated incretin and insulin secretory responses to a mixed meal. J Clin Endocrinol Metab. 2007;92:4678-85.

\section{Submit your next manuscript to BioMed Central and take full advantage of:}

- Convenient online submission

- Thorough peer review

- No space constraints or color figure charges

- Immediate publication on acceptance

- Inclusion in PubMed, CAS, Scopus and Google Scholar

- Research which is freely available for redistribution

Submit your manuscript at 